\title{
Correspondence
}

Cerebrovasc Dis 2011;32:302-303

DOI: $10.1159 / 000329380$

\section{Response to the Letter by A.J. Degnan Entitled 'Underestimating the Importance of Middle Cerebral Artery Atherosclerosis in Lacunar Stroke'}

\section{J.M. Wardlaw}

Division of Clinical Neurosciences, Western General Hospital, Edinburgh, UK

Commenting on our work [1], Dr. Degnan suggests that middle cerebral artery (MCA) atherosclerosis is widely recognised in non-Caucasian populations, is underresearched in Caucasian populations and questions the ability of transcranial Doppler sonography to identify MCA atheroma [2].

Our paper [1] addressed the question of whether most lacunar strokes had MCA (or other intracranial artery) stenosis as an underlying cause. The stenosis hypothesis suggests that the MCA atheroma either occludes the mouth of a lenticulostriate artery, releases emboli into the lenticulostriate artery or causes a lacunar stroke through haemodynamic disturbance. If MCA stenosis were responsible for most lacunar strokes (or even a moderate proportion of them), then we would have expected to find stenosis of $50 \%$ or more in at least some lacunar stroke patients. We argued for $50 \%$ or more by extension of the situation in the internal carotid arteries in the neck, where ipsilateral internal carotid artery territory stroke is unusual with less than $50 \%$ atheromatous stenosis in the proximal internal carotid artery [3]. We examined the patients a month or more after the stroke because, although we recognise that atheromatous remodelling can occur, we argued that a true atheromatous stenosis (as opposed to a stenosis during recanalisation of a thrombo-embolic occlusion) would not disappear very quickly.

We did not find any stenoses, and not only that, we found none in the cortical stroke patient controls (also Caucasian, and known to have large artery atheroma in the internal carotid arteries in the neck) either.

It would have been difficult to use other imaging techniques and achieve as large a sample size without introducing bias. Computed tomographic angiography requires a contrast injection (contraindicated in diabetics and renal impairment) and incurs a radiation dose; magnetic resonance angiography extends the magnetic resonance brain examination and may reduce compliance, and use of contrast is also contraindicated in renal impairment; neither is a perfect alternative to transcranial Doppler so- nography, as both may miss stenosis especially in restless patients. As stated in our paper, transcranial Doppler sonography is accurate for detecting $50 \%$ or more stenosis because these cause elevation in velocity and turbulence. We looked both for velocity changes and turbulence and found no velocity elevation outside the normal age range, and no asymmetry between the symptomatic and asymptomatic MCAs to suggest a velocity elevation on the symptomatic side even within the normal range.

We did find that the velocities fell with increasing amounts of leuko-araiosis, which we interpreted as indicating a reduction in blood flow with less brain to supply rather than that low flow causes white matter lesions.

MCA stenosis is a problem area. It is said to be more common in some ethnic groups, especially those of Chinese or Indian Asian and of African American origin. However, it is unclear whether, and how much, these ethnic differences reflect differences in diagnosis, in exposure to risk factors, or in some other variable, as opposed to true ethnic differences. Many papers on the topic of ethnic variation refer back to two seminal publications in the 1990s. The first, from the North Manhattan Stroke Study [4], included a total of 438 patients and found more MCA stenoses in Hispanic and African American groups than Whites, but even the highest prevalence of MCA stenosis was less than $10 \%$ and the study did not account for the much higher levels of vascular risk factors (smoking, hypertension, elevated cholesterol, low exercise levels) amongst Hispanics and Blacks than in Whites. The second was a retrospective case note review of only 77 patients which suggested that intracranial stenosis was more common amongst Blacks than Whites [5]. Retrospective case note reviews (particularly small ones) are notoriously unreliable.

To put this in perspective, in a recent (and probably not exhaustive) survey of the literature, we found 11 studies of MCA stenosis in different ethnic groups, mostly non-Caucasian, totalling 7,148 patients, in whom an MCA stenosis was found in 502 (23.0\%) patients, but the prevalence ranged from $0.4 \%$ in Caucasians to $54 \%$ in Singaporeans. Some studies were in asymptomatic patients (where the MCA stenosis rate tended to be lower) but most were in patients with a recent stroke. It was notable that not all stenoses were definitely related to the stroke (i.e. were in the wrong artery), many studies examined patients soon after stroke when a recanalising thrombus or embolus could mimic an atheromatous stenosis and, where stated, most strokes were ischaemic, in the MCA territory, cortical or large striatocapsular, i.e. not lacunar. This concurred with the proportions of clinical stroke subtypes, as in general, stenosis was commonest in patients with large cortical or posterior circulation clinical stroke subtypes, not lacunar ones. The final point was that few of these stud-

\section{KARGER}

Fax +41613061234 E-Mail karger@karger.ch www.karger.com
C 2011 S. Karger AG, Basel

$1015-9770 / 11 / 0323-0302 \$ 38.00 / 0$ 
ies accounted for differences in vascular risk factors (or even recorded them), but where these were recorded, very high proportions of patients with MCA stenosis had hypertension, diabetes, smoking, raised cholesterol or were inactive.

We agree that more methodologically sound and unbiased studies across different ethnic groups are required to determine the true prevalence of intracranial stenosis, overall, by ethnic group and by risk factor exposure, and more importantly, what to do about it.

\section{References}

1 Wardlaw JM, Doubal FN, Eadie E, Chappell F, Shuler K, Cvoro V: Little association between intracranial arterial stenosis and lacunar stroke. Cerebrovasc Dis 2011;31:12-18.

2 Degnan AJ: Underestimating the importance of middle cerebral artery atherosclerosis in lacunar stroke. Cerebrovasc Dis 2011;32:301.
3 Rothwell PM, Eliasziw M, Gutnikov SA, et al: Analysis of pooled data from the randomised controlled trials of endarterectomy for symptomatic carotid stenosis. Lancet 2003;361:107-116.

4 Sacco RL, Kargman DE, Gu Q, Zamanillo MC: Race-ethnicity and determinants of intracranial atherosclerotic cerebral infarction. The Northern Manhattan Stroke Study. Stroke 1995;26:14-20.

5 Wityk RJ, Lehman D, Klag M, Coresh J, Ahn H, Litt B: Race and sex differences in the distribution of cerebral atherosclerosis. Stroke 1996; 27:1974-1980.

J.M. Wardlaw

Division of Clinical Neurosciences, Western General Hospital Crewe Road

Edinburgh EH4 2XU (UK)

Tel. +44 131537 2943, E-Mail joanna.wardlaw@ed.ac.uk 